\title{
Multi-station synthesis of early twentieth century surface atmospheric electricity measurements for upper tropospheric properties
}

\author{
R. G. Harrison and A. J. Bennett \\ Department of Meteorology, University of Reading, P.O. Box 243, Earley Gate, Reading RG6 6BB, UK \\ Received: 22 August 2006 - Revised: 25 January 2007 - Accepted: 27 February 2007 - Published: 30 July 2007
}

\begin{abstract}
The vertical columnar current density in the global atmospheric electrical circuit depends on the local columnar resistance. A simple model for the columnar resistance is suggested, which separates the local boundary layer component from the upper troposphere cosmic ray component, and calculates the boundary layer component from a surface measurement of air conductivity. This theory is shown to provide reasonable agreement with observations. One application of the simple columnar model theory is to provide a basis for the synthesis of surface atmospheric electrical measurements made simultaneously at several European sites. Assuming the ionospheric potential to be common above all the sites, the theoretical air-earth current density present in the absence of a boundary layer columnar resistance can be found by extrapolation. This is denoted the free troposphere limit airearth current density, $J_{0}$. Using early surface data from 1909 when no ionospheric potential data are available for corroboration, $J_{0}$ is found to be $\sim 6 \mathrm{pA} \mathrm{m}^{-2}$, although this is subject to uncertainties in the data and limitations in the theory. Later (1966-1971) European balloon and surface data give $J_{0}=2.4 \mathrm{pA} \mathrm{m}^{-2}$.
\end{abstract}

\section{Introduction}

In the global atmospheric electrical circuit, a fair-weather current flows vertically between the ionosphere and the surface, which is related to the ionosphere-surface potential difference and the resistance of the atmospheric column. This charge transfer results because atmospheric air is weakly electrically conductive, as a result of radioactive ion production from Radon isotopes in continental surface air and cosmic ray ionisation elsewhere (Harrison and Carslaw, 2003). Long-term global circuit changes (Harrison, 2002; Märcz

Correspondence to: R. G. Harrison

(r.g.harrison@ reading.ac.uk) and Harrison, 2005) have been suggested to result from the twentieth century reduction in galactic cosmic ray ion production from increased solar activity (Lockwood et al., 1999; Carslaw et al., 2002), but the analysis of surface data from a single site is complicated as smoke and aerosol concentrations exert a local influence on surface atmospheric electrical measurements (Williams, 2003). Solar activity increased during the twentieth century, and a greater change occurred in approximately the first half of the century than the second half of the century (Lockwood, 2001). Most atmospheric electricity measurements in the first half of the twentieth century were made at the surface (Harrison, 2004), but a 1909 to 1959 reduction in lower atmosphere ion production is apparent in early European balloon-carried atmospheric electricity measurements (Harrison and Bennett, 2007).

The potential of the ionosphere with respect to the surface is a measurable parameter in the global atmospheric electrical circuit (Fig. 1). Direct measurements of the ionospheric potential are available in the second half of the twentieth century (e.g. Ungethüm, 1966; Imyanitov and Chubarina, 1967; Mülheisen, 1971; Markson, 1985). Although instrumented balloon ascents began in the late nineteenth century (Israël, 1970, 1973), these early ascents did not reach sufficient altitudes to permit the ionospheric potential to be directly calculated (Harrison and Bennett, 2007). Measurements of atmospheric electrical properties above the surface are, however, important in assessing global geophysical changes in atmospheric electricity, as regions of the troposphere above the continental boundary layer are relatively little affected by surface aerosol changes. To obtain quantitative data in the period before direct and routine balloon measurements, a new approach is developed here, in which simultaneous measurements from several surface observation sites are combined to reduce local surface effects.

A discussion of data analysis using multiple site measurements in the first half of the twentieth century was given by Israël (1973), based on the results of Hogg (1950). Hogg

Published by Copernicus Publications on behalf of the European Geosciences Union. 


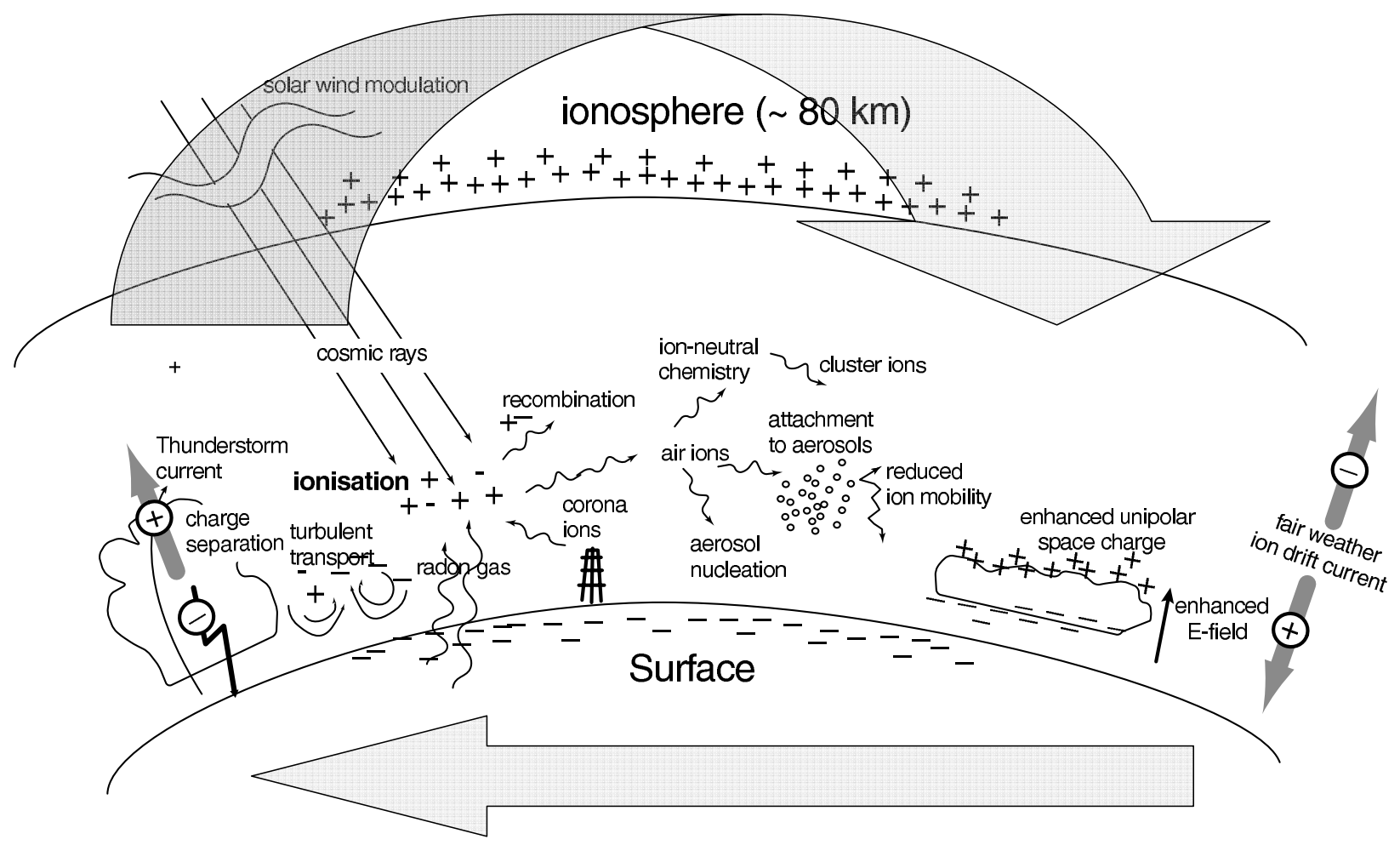

Fig. 1. Charge separation processes in the atmosphere (adapted from Harrison and Carslaw, 2003). Large arrows illustrate current flowing in the global circuit, in the conducting ionosphere and planetary surface. The fair weather current between ionosphere and surface results from the small finite conductivity of atmospheric air, principally due to cosmic ray ionisation.

found that, if the mean air-earth current density was plotted against the mean surface air conductivity, the measurements from different global sites clustered around a line. The nonlinear relationship showed that the air-earth current density $J_{z}$ increased with the surface air conductivity $\sigma_{s}$. For large values of $\sigma_{s}$ (i.e. increasingly clean air), $J_{z}$ extrapolated to $J_{z}>5 \mathrm{pA} \mathrm{m}^{-2}$, although an exact asymptotic value was not clearly identified. Using a vertical profile of the air conductivity, Hogg (1950) deduced the value for the ionospheric potential $V_{I}$ to be $340 \mathrm{kV}$.

\section{Theory for columnar properties}

The vertical columnar resistance $R_{c}$ determines the current density $J_{z}$ flowing between the ionosphere and the surface (Israël, 1970), and typically varies between 130 and $300 \mathrm{P} \Omega \mathrm{m}^{2}$ (Roble and Tzur, 1986). In principle, $R_{c}$ is defined by integrating the resistances of all atmospheric layers between the surface and ionospheric equipotential layer. In practice, $R_{c}$ can be found through solving the ion-aerosol balance equation (Harrison and Carslaw, 2003) for the air conductivity as a function of altitude, and then integrating the conductivity profile. This approach requires local aerosol and ion production rate profiles. The effect of aerosol on the conductivity profile is most substantial in the continental boundary layer (BL), but cosmic rays have an increasingly dominant effect above the boundary layer, in the free troposphere (FT) (Callahan et al., 1951). Accordingly, the total columnar resistance can be represented by a free troposphere component $R_{F T}$ and a boundary layer component $R_{B L}$, as

$R_{c}=R_{B L}+R_{F T}$.

The $R_{B L}$ term is variable, and depends on surface aerosol concentrations and mixing of the Radon isotopes. The $R_{F T}$ term is relatively constant, with variability from cosmic ion production changes with solar activity and volcanic aerosol injection into the stratosphere(Fig. 2a). Variation of cosmic ray ion production with geomagnetic latitude will also cause $R_{F T}$ to vary between sites located at substantially different latitudes.

A simple approximation is used here to represent $R_{B L}$. Analysing $R_{C}$ variations in 1966-1971 at Kew (Harrison, 2005 ), it was found that $R_{B L}$ was closely linked to the measured surface air conductivity. This can be understood in terms of a shallow layer of low conductivity air causing the lower atmosphere resistance. In such circumstances, $R_{B L}$ would be inversely proportional to the conductivity of the air in this layer (Fig. 2b). The exact relationship depends on the form of the conductivity profile chosen: it could be repre- 
(a)

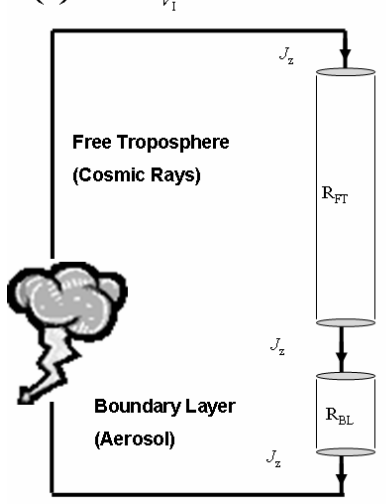

(b)

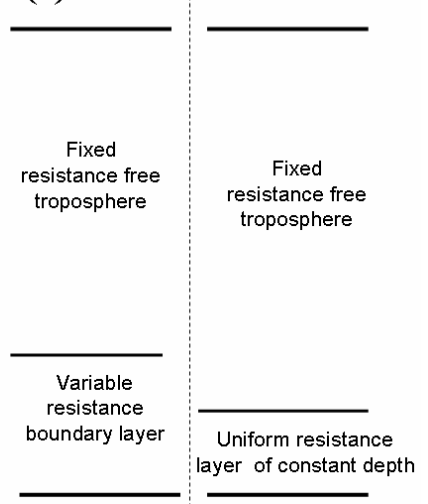

Fig. 2. (a) Columnar resistance in the global circuit. The columnar resistance $R_{C}$ determines the local global circuit current density $J_{z} . R_{C}$ consists of a boundary layer component $R_{B L}$ (from aerosol and radon isotopes) and a free troposphere component $R_{F T}$ (from cosmic rays). (b) $R_{B L}$ can be represented by a resistive layer of variable height, or approximated by a shallow fixed depth layer of variable resistance.

sented as a variable thickness layer with a varying conductivity, or an equivalent fixed height layer of constant conductivity. Using the surface air conductivity $\sigma_{s}$ to determine the constant resistance layer near the surface, (1) can be written as

$R_{c}=\frac{k}{\sigma_{s}}+R_{F T}$,

where $k$ is a proportionality constant related to the conductivity profile in the polluted layer, but can be equivalently understood physically as representing the height of a constant conductivity layer. Calculation of the terms in Eq. (2) is now considered further.

The air-earth current density $J_{z}$ is related to the ionospheric potential $V_{I}$ and columnar resistance $R_{c}$ by

$J_{z}=\frac{V_{I}}{R_{c}}$

which permits Eq. (2) to be written as

$\frac{V_{I}}{J_{z}}=\frac{k}{\sigma_{s}}+R_{F T}$.

Equation (4) links surface $\left(\sigma_{s}\right)$ and balloon sounded quantities $\left(V_{I}\right)$, through the column quantities of the air-earth current density $J_{z}$ and the free troposphere resistance $R_{F T}$. Making the low turbulence approximation (Tammet et al., 1996), Ohm's Law can be used to link surface measurements of PG $E_{s}$ and $\sigma_{s}$

$J_{z}=\sigma_{s} E_{s}$,

giving a further form for Eq. (4) as

$\frac{V_{I}}{E_{s}}=k+R_{F T} \sigma_{s}$.

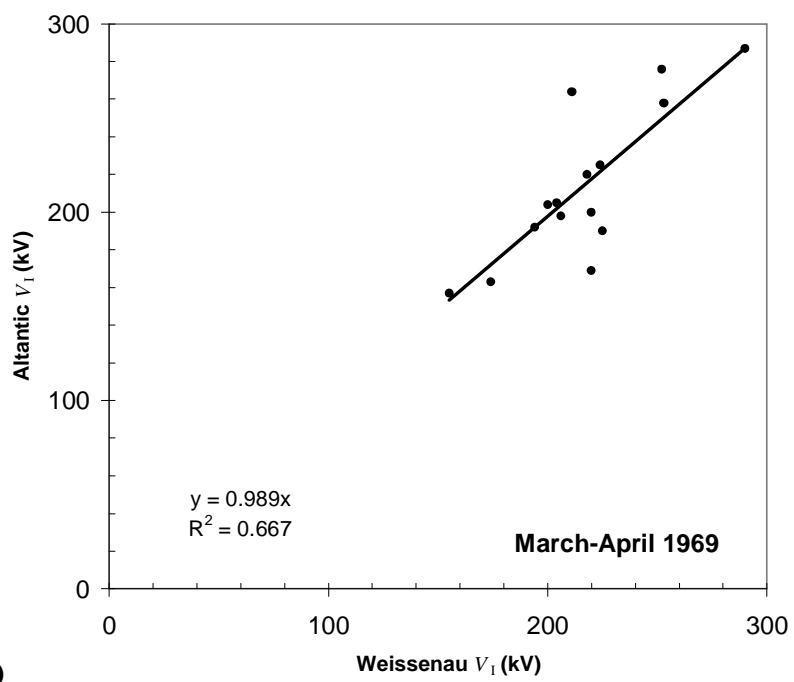

(a)

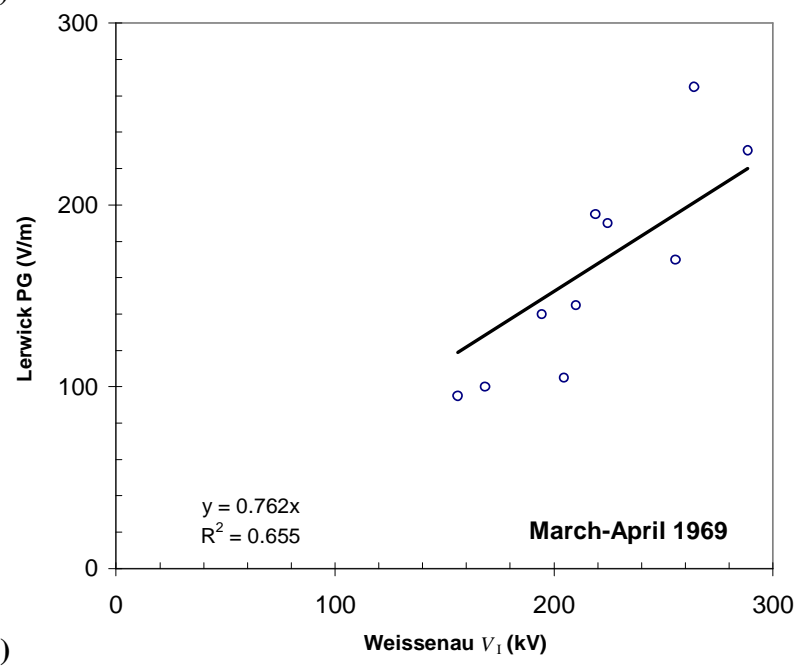

Fig. 3. Comparison of Weissenau ionospheric potential measurements with simultaneous measurements, when available, of (a) ionospheric potential determined over the north Atlantic using balloon soundings from the research ship Meteor (17 March to 2 April 1969), (b) the surface potential gradient (PG), measured at Lerwick in fair weather or non-hydrometeor conditions (17 March to 2 April 1969).

Data to test the validity of the approximations in deriving Eq. (6) are rare, however the ionospheric potential measurements by R.Mülheisen at Weissenau, Germany (e.g. Mülheisen, 1977), and the frequent Wilson instrument airearth current density and PG measurements made at Kew by the UK Met Office (Harrison and Ingram, 2005) were occasionally coincident and provide suitable data for analysis. Some of the daily measurements of $J_{z}$ and $\sigma_{s}$ at Kew coincided with $V_{I}$ soundings made from Weissenau in 1966 1971 (Harrison, 2005).

A necessary assumption for this comparison is that that the $V_{I}$ soundings made from Weissenau also represented the 


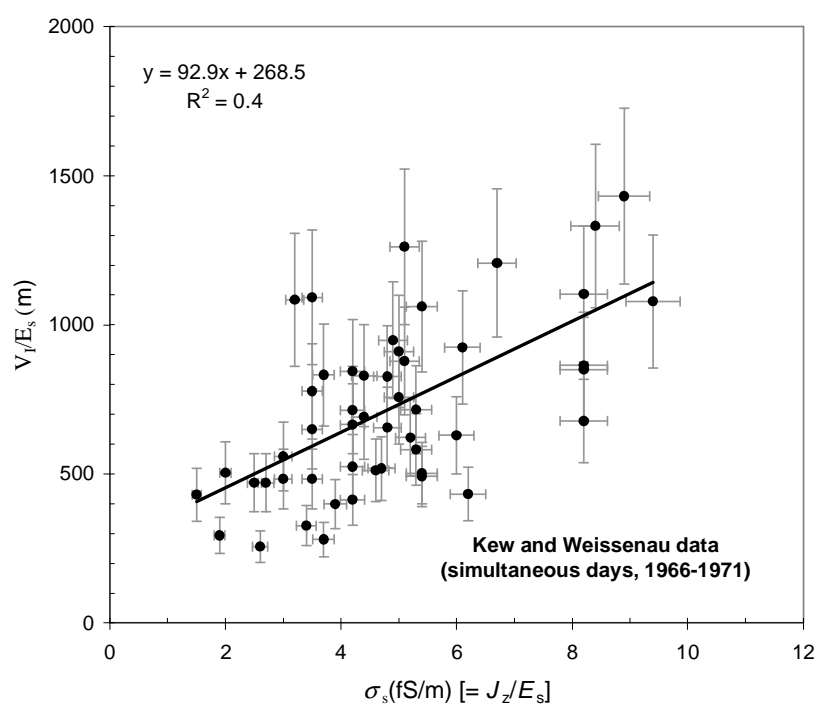

Fig. 4. Daily measurements of ionospheric potential $V_{I}$ (over Weissenau) and surface measurements from Kew on the same days of potential gradient $E_{S}$ and air conductivity $\sigma_{S}$, with $\sigma_{S}$ plotted against $V_{I} / E_{S}$. A $20 \%$ worst-case uncertainty has been assumed for $V_{I}$, and $5 \%$ for $E_{S}$ and $\sigma_{s}$ (data from Harrison, 2005).

$V_{I}$ above Kew, i.e. that a common equipotential surface existed above both sites, as expected from the global circuit model. Confirmation of this spatial equipotential assumption requires, at least, corroboration with simultaneous measurements in the same region. Surface measurements were made throughout this period at Lerwick, Shetland, and further $V_{I}$ soundings are available made in the western Atlantic. The $V_{I}$ measurements were led by Mülheisen, using the Meteor research ship. Many of the soundings made from the $\mathrm{Me}$ teor were simultaneous with soundings made from Weissenau (Mülheisen, 1971). Figure 3a shows a comparison between $V_{I}$ soundings made at Weissenau and those from the Meteor, during the observation period in March and April 1969, from data tabulated by Buduko (1971). There is close agreement in the $V_{I}$ values obtained at the two sites. Figure $3 \mathrm{~b}$ shows a comparison between Lerwick PG measurements and the Weissenau $V_{I}$ soundings, for PG measurements simultaneous with the soundings when the conditions at Lerwick were either classified as fair weather or no hydrometeors were recorded. There is a linear relationship between the Lerwick PG and the Weissenau $V_{I}$, which implies that the surface PG at Lerwick was modulated by the ionospheric potential above. This agreement between the measurements at Lerwick, Meteor and Weissenau, which geographically bound a triangle including Kew Observatory in the southern UK, provides the basis for considering the Weissenau $V_{I}$ soundings as representative of the ionospheric potential above Kew.

Figure 4 shows the comparison between the surface and balloon measurements, plotted in terms of the model repre- sented by Eq. (6). The Kew surface measurements using the Wilson technique determined $E_{s}$ and $J_{z}$ independently, as $E_{S}$ was obtained by measuring the induced potential on the sensing plate, and $J_{z}$ from the rate of change of $E_{s}$. (The local air conductivity was calculated assuming Ohms Law' i.e. $\left.\sigma_{s}=J_{z} / E_{s}\right)$. Figure 4 can therefore equivalently be regarded as a plot of $\left(V_{I} / E_{S}\right)$ against $\left(J_{S} / E_{S}\right)$, in which all three quantities are determined separately. The model provides a significant fit to the experimental data ( 49 points, $r=0.61$ ), showing that Eq. (6) does provide a representation of the physical processes concerned, under the assumptions made. Figure 4 also allows determination of $R_{F T}=(92.9 \pm 18) \mathrm{P} \Omega \mathrm{m}^{2}$ and $k=(268 \pm 92) \mathrm{m}$. This indicates that $R_{B L}$ can be represented by an equivalent constant conductivity layer of fixed depth $268 \mathrm{~m}$, with the layer containing air of conductivity equal to the measured surface conductivity. The mean values of air-earth current density at Kew for the same period (1966-1971) was $J_{z}=(1.58 \pm 0.04) \mathrm{pA} \mathrm{m}^{-2}$ and the mean ionospheric potential $V_{I}=(217 \pm 4) \mathrm{kV}$, giving a columnar resistance at that site of $R_{C}=137 \mathrm{P} \Omega \mathrm{m}^{2}$ calculated from Eq. (3). Applying Eq. (1) allows $R_{B L}$ to be found from the values of $R_{c}$ and $R_{F T}$.

A theoretical limiting case can be considered, in which only the upper atmosphere term contributes resistance and there is no contribution from the lower atmosphere, i.e. when $R_{B L}=0$. In such conditions, the current density flowing would be increased, as $R_{C}=R_{F T}$. The current density in these circumstances is denoted the free troposphere limit air-earth current density $J_{0} . J_{0}$ provides a measure of upper properties of the columnar independently of the surface properties. For the 1966-1971 values analysed, $J_{0}=2.4 \mathrm{p} \mathrm{Am}^{-2}$.

\section{Extension to historical atmospheric electrical data}

\subsection{Formulation}

Many early surface atmospheric electricity records exist of Potential Gradient measurements. Some European sites also measured the air-earth current density $J_{z}$ and surface ion properties (number concentrations and mobilities) or the air conductivity $\sigma_{s}$. A summary of data sources is given in Harrison (2004). Whilst these could in principle provide useful data for Eq. (6), there are, as mentioned earlier, no direct measurements of $V_{I}$ from the first half of the twentieth century. This precludes the use of Eq. (6) at a single site. However as $V_{I}$ is a global equipotential, the surface atmospheric electrical measurements made simultaneously at different sites will all have experienced the same $V_{I}$ above them (Fig. 5). A set of simultaneous measurements from several sites consequently contains information about the average global circuit properties common to them all, and the ratios of their local columnar resistances (Harrison, 2007).

If a plot of $J_{z}$ against $\sigma_{s}$ were made for a set of simultaneous measurements from different sites (e.g. Hogg, 1950), $J_{z}$ 


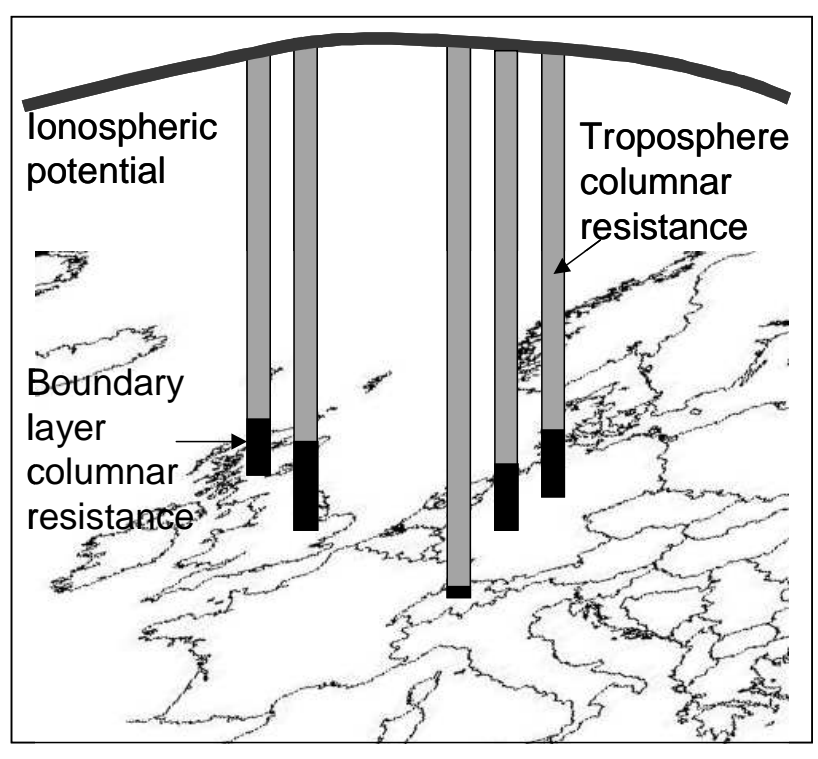

Fig. 5. Schematic of the effect of global circuit changes on simultaneous measurements of the air-earth current density at different European sites. The ionospheric potential has a constant value above all the sites. The columnar resistance consists of a free troposphere component (shaded dark gray), and a boundary layer part component (shaded black).

would increase non-linearly with $\sigma_{s}$, and approach an asymptotic value. Physically, this asymptotic value arises when the (local) lower atmosphere resistance term $\left(R_{B L}\right)$ becomes negligible compared with the (global) upper atmosphere resistance $\left(R_{F T}\right)$. In the limit as $\sigma_{s} \rightarrow \infty$, the asymptotic value of current density becomes the free troposphere current density $J_{0}$. This limit provides a method for determining $J_{0}$ from surface measurements, by using the linear theory in the limit as $\left(1 / \sigma_{s}\right) \rightarrow 0$.

Equation (4) can be rearranged to give

$\frac{1}{J_{z}}=\left(\frac{k}{V_{I}}\right) \frac{1}{\sigma_{s}}+\frac{R_{F T}}{V_{I}}$

This separates the boundary layer effects (first term on RHS) from the free troposphere effects (second term on RHS), which both determine the air-earth current density $J_{z}$ at a specific location. This form of the equation is particularly useful as the second RHS term is independent of the boundary layer properties $k$ and $\sigma_{s}$. If the boundary layer is considered to become highly electrically conductive, i.e. allowing $\left(1 / \sigma_{s}\right) \rightarrow 0$, only the free troposphere term remains. In this theoretical limit, the corresponding value of $J_{z}$ would be that corresponding to $R_{B L}=0$, which is the limiting condition $J_{z}=J_{0}$. Equation (7) therefore provides a basis for the calculation of $J_{0}$ from surface measurements alone, if simultaneous, multiple site, values of $J_{z}$ and $\sigma_{s}$ are available.

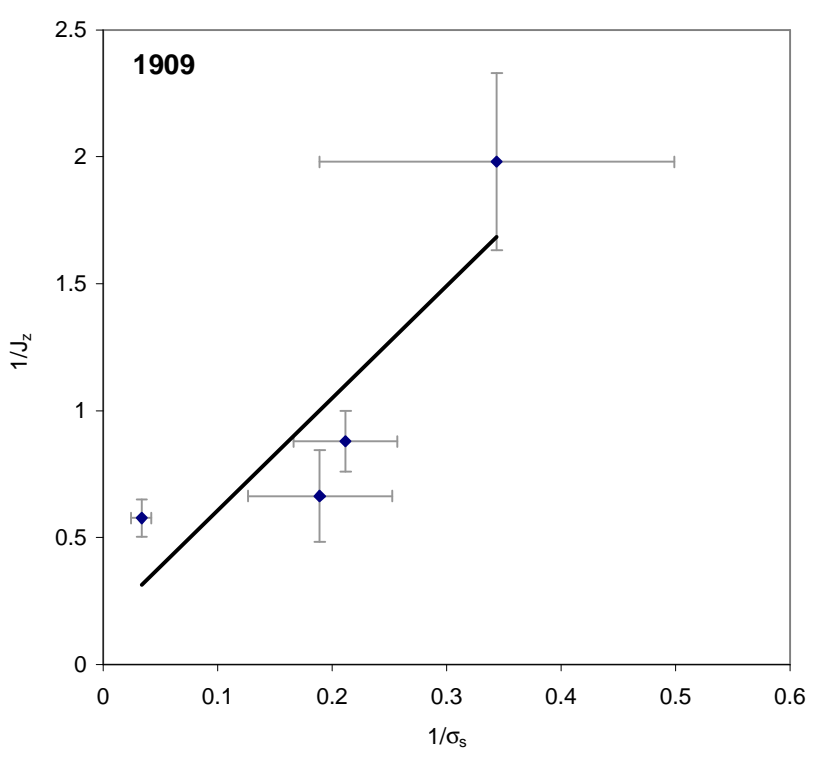

(a)

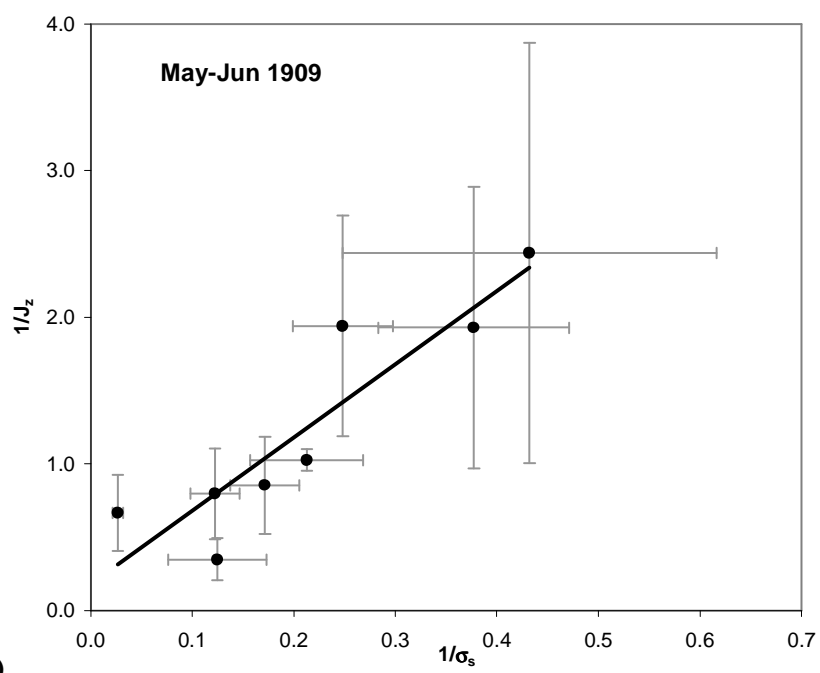

Fig. 6. Measured air-earth current $J_{z}$ and $\sigma_{s}$ plotted according to Eq. (7) for (a) Davos, Munich, Kew and Potsdam in 1909 and (b) for Davos, Munich, Kew, Potsdam and Edinburgh in May-June 1909. (Error bars are from one standard deviation. For Davos, Munich and Potsdam in (b), the fractional standard deviation was assumed to be the same as that for Kew.)

\subsection{Test with 1909 data}

Simultaneous data sets are relatively rare in atmospheric electricity, but such measurements were more common in the first part of the twentieth century. Measurements from the early twentieth century, from Europe in 1909, have been used to test Eq. (7). These are:

1. Annual measurements of $\sigma_{s}$ and $J_{z}$, given as monthly values for Munich, Davos, Kew and Potsdam in 1909 (Dobson, 1914) 
Table 1. Annual averages for surface air conductivity and air-earth current density for Potsdam, Kew, Munich and Davos in 1909.

\begin{tabular}{lcccc}
\hline Site & \multicolumn{2}{c}{ Total conductivity ( $\mathrm{fS} \mathrm{m}^{-1}$ ) } & \multicolumn{2}{c}{ Air-earth current density $\left(\mathrm{pA} \mathrm{m}^{-2}\right)$} \\
& Annual mean & standard deviation & Annual mean & standard deviation \\
\hline Potsdam & 4.72 & 1.0 & 1.14 & 0.2 \\
Kew & 2.91 & 1.3 & 0.5 & 0.1 \\
Munich & 5.28 & 1.8 & 1.51 & 0.4 \\
Davos & 29.88 & 7.9 & 1.73 & 0.2 \\
\hline
\end{tabular}

Table 2. Averages for surface air conductivity and air-earth current density Davos, Munich, Kew, Potsdam and Edinburgh, for MayJune 1909.

\begin{tabular}{lcc}
\hline Site & $\begin{array}{c}\text { Total conductivity } \\
\mathrm{fS} \mathrm{m}^{-1}\end{array}$ & $\begin{array}{c}\text { Air-earth current density } \\
\mathrm{pA} \mathrm{m}^{-2}\end{array}$ \\
\hline Edinburgh Obs & 2.31 & 0.41 \\
Edinburgh Obs & 2.65 & 0.52 \\
Waverley Park & 4.70 & 0.97 \\
Blackford Hills & 8.02 & 2.87 \\
Kew & 4.03 & 0.52 \\
Munich & 8.17 & 1.26 \\
Davos & 37.30 & 1.5 \\
Potsdam & 5.83 & 1.17 \\
\hline
\end{tabular}

2. May-June values for $1909 \sigma_{s}$ and $I_{z}$ for Munich, Davos, Kew and Potsdam (Dobson, 1914) and Edinburgh (Carse and MacOwan, 1910).

These measurements sites all have, in common, air within a continental boundary layer, but a range of different air pollution conditions. Tables 1 and 2 give values of $\sigma_{s}$ and $J_{z}$ from these sources.

Figure 6 plots the data values as $\left(1 / J_{z}\right)$ against $\left(1 / \sigma_{s}\right)$, for (a) the annual values and (b) the May-June values, with leastsquares straight lines added. In Fig. 6a, the use of an annual value compensates to some extent for different seasonal cycles between the different sites, however there are only four values. In Fig. 6b, extra points are available, but the validation of Eq. (6) may be less appropriate as only a short period of data (2 months) is available, and seasonal effects will not be removed in the same way. It is clear from both plots, however, that extrapolation to $\left(1 / \sigma_{s}\right)=0$ provides a finite positive value of $J_{0}$. Using the annual values (Fig. 6a), the most probable $J_{0}=6.0 \mathrm{pA} \mathrm{m}^{-2}$, with a (1 standard error) lower limit of $1.7 \mathrm{pA} \mathrm{m}^{-2}$. For summer values (Fig. 6b), the linear fit gives $J_{0}=5.6 \mathrm{pA} \mathrm{m}^{-2}$ (lower limit of $1.3 \mathrm{pA} \mathrm{m}^{-2}$ ).

\section{Conclusions}

A multi-station synthesis approach seems particularly useful for determining global circuit properties in the period before balloon or aircraft ascents reached sufficient altitudes to obtain direct measurements of the ionospheric potential, i.e. for the first half of the twentieth century, when many sets of surface measurements are available.

The use of a simple approximation to the boundary layer columnar resistance provides a basis for a multi-station synthesis of atmospheric electricity measurements, which permits estimation of electrical properties above the boundary layer without using data requiring balloon ascents. The method assumes that the shape and variations in the conductivity profile at each site can be represented in a similar way on average, although the absolute surface layer columnar resistances are allowed to be different. For the sites examined, the variability in the data is likely to dominate over the uniform conductivity profile assumption. At many sites, such as the Marsta Observatory in Sweden (Israelsson and Tammet, 2001), the winter boundary layer shows so little variability that surface measurements in the PG exhibit the global circuit (Carnegie) variation in the diurnal data. The regularity in this behaviour across many years indicates that a uniform conductivity profile assumption is reasonable.

The free tropospheric current $J_{0}$ derived for 1909 in Europe is poorly constrained because of the variability in the available data and the limitations of the linear theory applied, but is estimated to be greater than $1.7 \mathrm{pA} \mathrm{m}^{-2}$, with a probable value of $6 \mathrm{pA} \mathrm{m}^{-2}$. This compares with the direct determination of $J_{0}=2.4 \mathrm{pA} \mathrm{m}^{-2}$ obtained in 1966-1971, for a similar region. This suggests a reduction in the global circuit current density, qualitatively consistent with the reduction in cosmic ray ion production determined in other studies for the first half of the twentieth century.

Acknowledgements. AJB acknowledges a studentship from the Natural Environment Research Council (NERC). F. Märcz (Geodetic Institute of the Hungarian Academy of Sciences) provided helpful comments.

Edited by: N. Crosby and M. Rycroft

Reviewed by: two anonymous referees 


\section{References}

Budyko, M. I.: Results of observations of atmospheric electricity (The World Network, Additional Issue 1965-1969), USSR Chief Administration of the Hydro-Meteorological Service, Leningrad, 1971.

Callahan, R. C., Coroniti, S. C., Parziale, A .J., and Patten, R.: Electrical conductivity of air in the troposphere, J. Geophys. Res., 56, 545-551, 1951.

Carse, G. A. and MacOwan, D.: Observations of the earth-air electric current and the atmospheric potential gradient, Proc. Roy. Soc. Edin., 30, 32, 460-465, 1910.

Carslaw, K. S., Harrison, R. G., and Kirkby, J.: Cosmic rays, clouds and climate, Science, 298, 5599, 732-1737, 2002.

Dobson, G.: A comparison of the electrical conditions of the atmosphere at Kew and Eskdalemuir with notes on observations of atmospheric electricity made in other countries, Geophysical Memoirs, 7, 155-169, Meteorological Office, His Majesty's Stationery Office, 1914.

Harrison, R. G.: Twentieth century secular decrease in the atmospheric electric circuit, Geophys. Res. Lett., 29(14), 1660, doi:10.1029/2002GL014878, 2002.

Harrison, R. G.: The global atmospheric electrical circuit and climate, Surv. Geophys., 24, 441-484, 2004.

Harrison, R. G.: Columnar resistance changes in urban air, J. Atmos. Solar-Terr. Phys., 67(8-9), 763-773, 2005.

Harrison, R. G.: Electrical properties of surface atmospheric air at Eskdalemuir, 1909-1911, Atmos. Res., 84(2), 182-188, 2007.

Harrison, R. G., and Carslaw, K. S.: Ion-aerosol-cloud processes in the lower atmosphere, Rev. Geophys., 41(3), 1012, doi:10.1029/2002RG000114, 2003.

Harrison, R. G. and Ingram, W. J.: Air-earth current measurements at Kew, London, 1909-1979, Atmos. Res., 76(1-4), 4964, doi:10.1016/j.atmosres.2004.11.022, 2004.

Harrison, R. G. and Carslaw, K. S.: Ion-aerosol-cloud processes in the lower atmosphere, Rev. Geophys., 41(3), 1012, doi:10.1029/2002RG000114, 2003.

Harrison, R. G. and Bennett, A. J.: Cosmic ray and air conductivity profiles retrieved from early twentieth century balloon soundings of the lower troposphere, Atmos. Res., 84, 2, 182-188, 2007.

Hogg, A. R.: Air-earth current observations in various localities, Arch. Meteor. Wien A, 3, 40-55, 1950.

Imyanitov, I. M. and Chubarina, E. V.: Electricity of the free atmosphere, Israel program for Scientific Translations, Jerusalem, 1967.
Israël, H.: Atmospheric Electricity, Vol. 1 (Fundamentals, Conductivity, Ions) (Problems of Cosmic Physics, Vol. 29), Israel Program for Scientific Translations, Jerusalem, 1970.

Israël, H.: Atmospheric Electricity, Vol. 2 (Fields, charges, currents) (Problems of Cosmic Physics, Vol. 29), Israel Program for Scientific Translations, Jerusalem, 1973.

Israelsson, S. and Tammet, H.: Variation of fair weather atmospheric electricity at Marsta Observatory, Sweden, 1993-1998, J. Atmos. Solar-Terr. Phys., 63, 1693-1703, 2001.

Lockwood, M.: Long-term variations in the magnetic fields of the Sun and the heliosphere: their origin, effects, and implications, J. Geophys. Res., 106(A8), 16021-16038, 2001.

Lockwood, M., Stamper, R., and Wild, M. N.: A doubling of the sun's coronal magnetic field during the last 100 years, Nature, 399, 437-439, 1999.

Märcz, F. and Harrison, R. G.: Further signatures of long-term changes in atmospheric electrical parameters observed in $\mathrm{Eu}-$ rope, Ann. Geophys., 23, 1987-1995, 2005, http://www.ann-geophys.net/23/1987/2005/.

Markson, R.: Aircraft measurements of the atmospheric electrical global circuit during the period 1971-1984, J. Geophys. Res., 90(D4), 5967-5977, 1985.

Mülheisen, R. P.: New determination of the air-earth current over the ocean and measurements of ionospheric potentials, Pure Appl. Geophys., 84, 112-115, 1971.

Mülheisen, R.: The global circuit and its parameters, in: Electrical Processes in Atmospheres, edited by: Dolezalek, H. and Reiter, R., Steinkopf Verlag, 467-476, 1977.

Roble, R. and Tzur, I.: The Global Atmospheric-Electrical Circuit, Chapter 15, in: The Earth's Electrical Environment, edited by: Krider, E. P. and Roble, R., National Academies Press, Washington D.C., 206-231, 1986.

Tammet, H., Israelsson, S., Knudsen, E., and Tuomi, T. J.: Effective area of a horizontal long-wire antenna collecting the atmospheric electric vertical current, J. Geophys. Res., 101(D23), 2967129 678, doi:10.1029/96JD02131, 1996.

Ungethüm, E.: Measurements of the electric field in the free atmosphere during IQSY 1964-1965, Meteorological Report Series 3, Marsta Observatory, University of Uppsala, 1966.

Williams, E. R.: Comment to "Twentieth century secular decrease in the atmospheric potential gradient" by Giles Harrison, Geophys. Res. Lett., 30(5), 1803, doi:10.1029/2003GL017094, 2003. 